\title{
Design of Nested H slot Passive UHF RFID Tag
}

\author{
SudhaSurwase, Ravi Yadahalli, Shankar Nawale
}

\begin{abstract}
RFID is a short distance communication system which comprises of a RFID tag, a RFID reader and a personal computer with desired software that can maintain the related information. These RFID tags can be of active or passive types. This paper focuses on design, simulation and fabrication of passive ultra-high frequency RFID tag (microchip and an antenna) which resonates at the frequency $866 \mathrm{MHz}$ in the Industrial Scientific Medical Band. The nested $\mathrm{H}$-slot inverted-F microstrip antenna structure is used for the design of passive RFID tag. It examines the specific tag geometry and its characteristics to optimize the PIFA antenna and in turn RFID tag's performance.
\end{abstract}

Keywords-Impedance, PIFA, RFID tag, UHF

\section{INTRODUCTION}

The most simplest and straightforward approach for (Radio Frequency Identification ) RFID communication is the near field coupling and has components as shown in fig. 1 but has drawback that as the frequency increases, the range over which communication may happen between reader and tag decreases. In themid-21st century, RFID tags with smaller size were implemented and advancements in the IC technology were in its boom. The number of components wasreduced to two, a single CMOS IC and an antenna. Thus, it results in the emerging of RFID tags with different shapes and characteristics. The RFID technology assigns a unique identifier to each product and allows significant development in wireless monitoring and control applications. The UHF RFID uses backscattering communication.The backscattering coupling uses electromagnetic waves and inductive coupling uses magnetic field to exchange data between tag and reader [2].TheRFID reader generates an electro-magnetic field which induces a current into the tag's antenna. The current is used to power the chip. In passive tags the current also charges a condenser which assures uninterrupted power for the chip. Hence, RFID communication becomes the noncontact, non-line-of-sight communication, the long distance can be covered with high-speed reading, and other advantages make the UHF

Revised Manuscript Received on October 20, 2020.

* Correspondence Author

SudhaVijaysinhSurwase*, Department of Electronics and Telecommunication Engineering, SKN Sinhgad College of Engineering, Pandharpur, Sholapur, MS, India. Email: sudha.surwase@sknscoe.ac.in

Ravi M. Yadahalli, Department of Electronics and Telecommunication EngineeringS G. Balekundri Institute of Technology,Belagavi, Karnataka, India. Email: ravimyadahalli@gmail.com

Shankar DattatrayaNawale, Professor \& Principal N B NavaleSinhgad College of Engineering, Kegaon, Solapur, MS, India, 413255 Email: shankarnawale125@gmail.com

(C) The Authors. Published by Blue Eyes Intelligence Engineering and Sciences Publication (BEIESP). This is an open access article under the CC BY-NC-ND license (http://creativecommons.org/licenses/by-nc-nd/4.0/)
RFID becoming the most popular automatic identification technology around the world.Theimportant characteristics of RFID systems are the operating frequency and the resultingrange of the system. The frequency at which the reader transmitsis the operating frequency of an RFID system. The transmission frequency of the transponder is disregarded [1]. In most cases it is the same as the transmission frequency of the reader (load modulation, backscatter). However, the transponder's 'transmitting power' may be set several powers of ten lower than that of the reader [1].

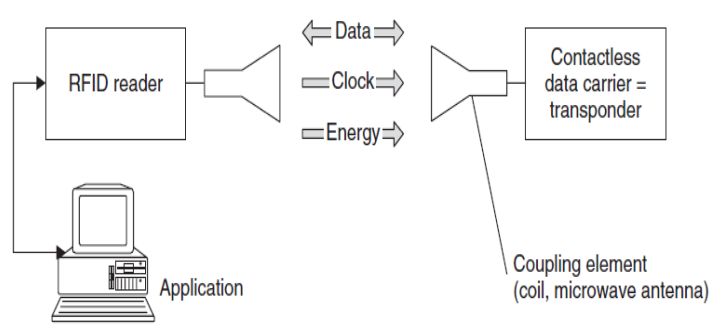

Fig.1: Components of RFID systems [1]

\section{RFID TAGS AND ANTENNAS}

\section{A. ACTIVE AND PASSIVE TAGS}

An essential and very important feature of RFID systems is the power supply to the transponder (antenna). Passive transponders do not have their own power supply, and therefore all power required for the operation of a passive transponder must be drawn from the (electrical/magnetic) field of the reader.Table 1 below shows the comparison of active and passive tags.

TABle.1. Comparison OF ACTIVE AND PASsive TAgs [3]

\begin{tabular}{|l|l|l|}
\hline & \multicolumn{1}{|c|}{ Active } & \multicolumn{1}{c|}{ Passive } \\
\hline Signal Strength & Stronger & Weaker \\
\hline $\begin{array}{l}\text { Signal } \\
\text { availability }\end{array}$ & Always on & $\begin{array}{l}\text { Responds when } \\
\text { read }\end{array}$ \\
\hline Size & Larger & Smaller \\
\hline Initial cost & Higher & Lower \\
\hline Maintenance & $\begin{array}{l}\text { Replace every } \\
\text { 2-3 years }\end{array}$ & Indefinite lifetime \\
\hline Environment & $\begin{array}{l}\text { Available for all } \\
\text { environments }\end{array}$ & $\begin{array}{l}\text { Available for all } \\
\text { environments }\end{array}$ \\
\hline
\end{tabular}

By compairing, the cost of active tags is much higher than the passive tags. The signal availability as 'always on' for the active tags, adds to its higher cost.

\section{B. PLANAR INVERTED F ANTENNAS}

A shorted patch antenna fed by an aperture-coupled feed is a promising design for achieving broadband operation [2]. As shown in fig.2, there is a $\mathrm{H}$ shaped coupling slot and a patch of width $\mathrm{W}$ and length $\mathrm{L}$ shorted to the ground plane.

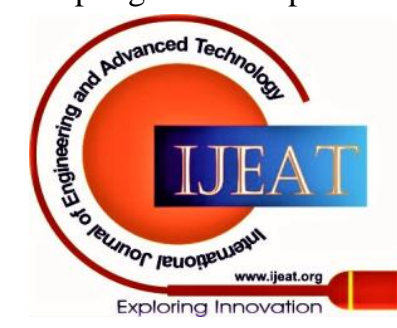




\section{Design of Nested H slot Passive UHF RFID Tag}

The size of a planar inverted $F$ antenna can be determined approximately from equation [3]

$$
f 0=\frac{C}{4(W+L)}
$$

Where, $\mathrm{C}$ is the velocity of light and $\mathrm{f}_{0}$ is operating frequency

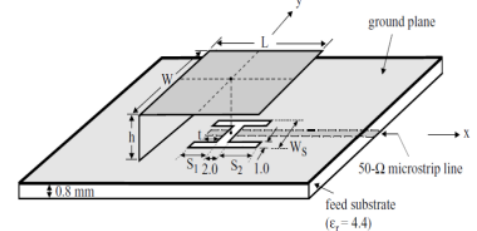

Fig. 2: Geometry of Broadband aperture coupled shorted patch antenna [2]

\section{IMPEDANCE MATCHING AND SIZE REDUCTION IN PIFA ANTENNAS}

Two size reduction strategies can be used successfully to design RFID tags: meandering and inverted-F structures.

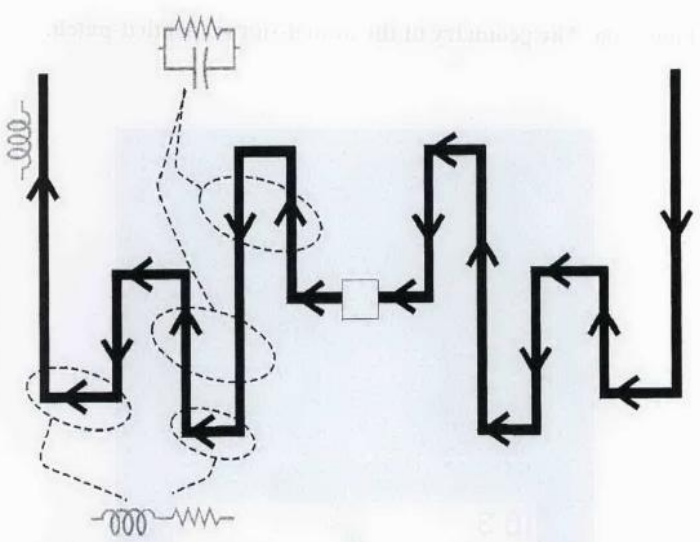

Fig. 3. Meander line antenna with unequal turns affects the inductance [5]

Both require a single or even multiple folding of the radiating body. Fig. 3 shows the meandered antenna with unequal turns which can be used to increase the gain. The inverted-F antennas additionally include a finite approximation of a ground planeas shown in fig.4 [5].

The nested slot can be used for the impedance matching. Due to the inductive reactance of a nonresonant slot, the feeding strategy has the relevant capability of complex impedance matching, even when the tag is attached onto a high-permittivity substrate[5]. The discontinuity in the structure provides energy storage. The antenna impedance can be changed by changing the aspect ratio i.e. parameters ' $a$ ' and ' $b$ ' (the dimensions of the slot).

Fig. 5 shows the Qualitative behavior of antenna impedance, chip impedance, and read range as functions of frequency for a typical RFID tag [6]. The tag resonates at the frequency over which peak is obtained and bandwidth is the range of frquency over which tag offers minimum read range.

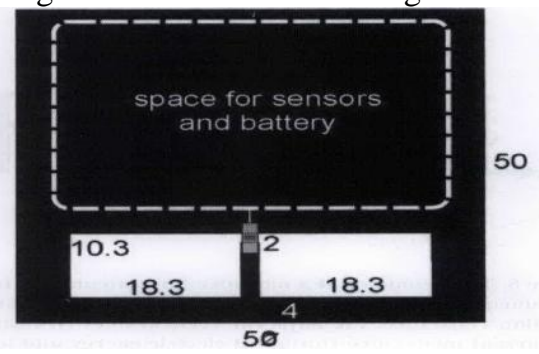

Fig. 4: An example of RFID tag for better impedance matching[5]

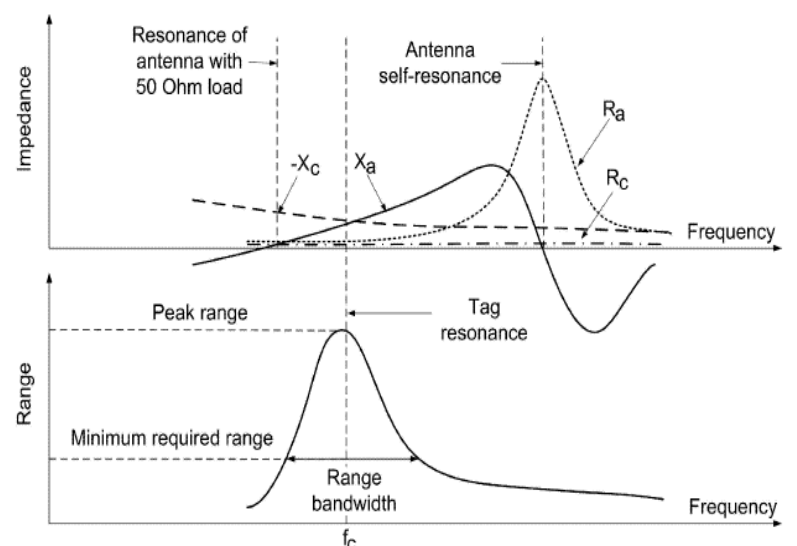

Fig. 5. Antenna impedance, chip impedance, and readrange as functions of frequency for a typical RFID tag

\section{THE PROPOSED METHODOLOGY}

The passive RFID tag antenna is simulated using CST Studio. The dimensions of the tag antenna are decided based on the relations as given by [7].

TABLE- II : DESIGN PARAMETER LIST

\begin{tabular}{|c|c|}
\hline Parameter & Dimensions in $\mathbf{~ m m}$ \\
\hline s1 & 5 \\
\hline lg & 60 \\
\hline s2 & 2 \\
\hline a & 15 \\
\hline l & 52.5 \\
\hline g & 1.5 \\
\hline b & 5 \\
\hline p & 14 \\
\hline wg & 60 \\
\hline ld & 7.5 \\
\hline a1 & 9 \\
\hline a2 & 3 \\
\hline s & 10 \\
\hline t & 0.05 \\
\hline hs & 4 \\
\hline
\end{tabular}

The length of the patch is decided as $\lambda$ eff $/ 4$ where $\lambda$ eff is the effective wavelength obtained from $\varepsilon_{\text {eff. }}$ Fig. 6 shows the perspective view of the antenna which is simulated using CST microwave studio.

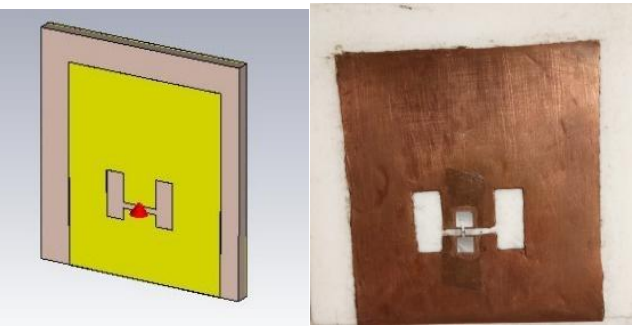

Fig. 6: Perspective view of simulated antenna and the fabricated antenna

The adhesive Copper sheet with thickness $0.05 \mathrm{~mm}$ in actual fabrication is folded from the ground plane to the front side.

Published By:

Blue Eyes Intelligence Engineering and Sciences Publication

(C) Copyright: All rights reserved.

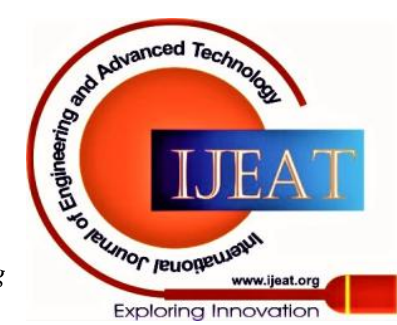




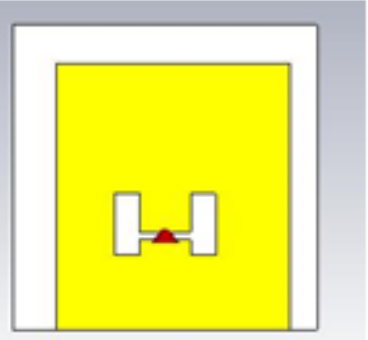

Fig. 7(a): Front view of simulated antenna

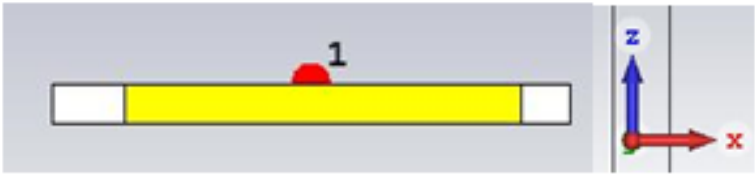

Fig. 7(b): Bottom view of designed tag

Fig. 7(a) and Fig. 7(b) shows the front and bottom view of the RFID tag simulated using CST microwave studio. The PIFA fold is as shown in the bottom view of the designed tag. As per the maximum power transfer theorem, the RFID antenna impedance should be matched to the microchip impedance which is generally capacitive in nature.

\section{RESULT ANALYSIS}

The antenna impedance is thus complex conjugate of the microchip impedance to assure maximum range. The designed RFID antenna has real part of impedance as 12.94 and imaginary part of impedance as 142.75 ohms as shown in fig. 8(a) and 8(b) respectively at $866 \mathrm{MHz}$.

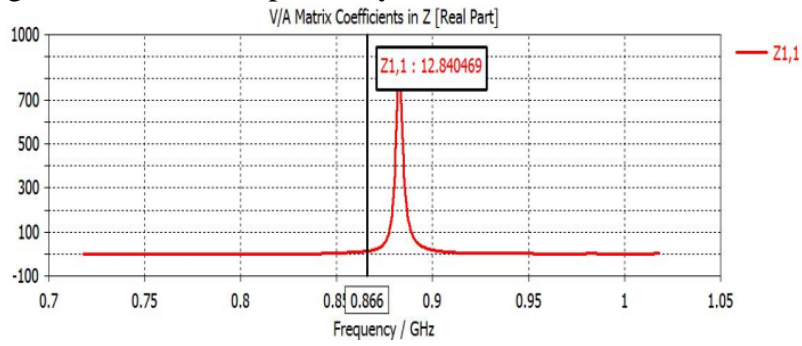

Fig. 8(a): Real part of impedance

The impedance of the tag can be varied by changing the various parameters as $\mathrm{p}$

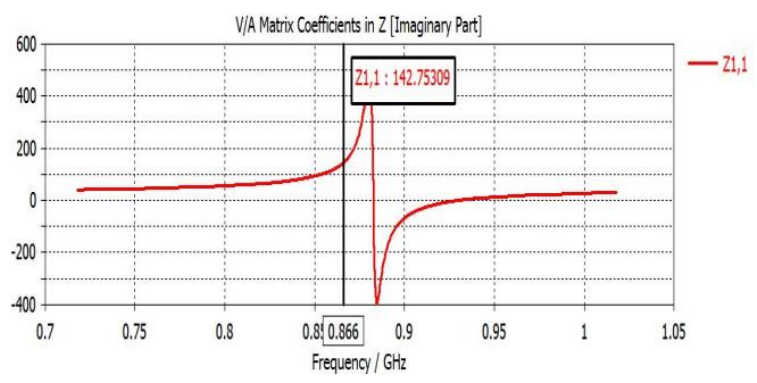

Fig. 8(b): Imaginary part of impedance

(the distance of lower section of centre slot to the PIFA fold), a1, a2 (the vertical dimensions of the tag above and below the centre slot) and b (the width of the slot i.e. Distance between the centre of micrchip slot to the $\mathrm{H}$ slot width) [8]. The experimental work has been performed by varying the tag parameters. The parameter ' $a$ ' and ' $b$ ' are varied and corresponding tag impedance is noted. It has been found that with the decrease in dimensions ' $a$ ' and ' $b$ ' of the tag antenna, the impedance of the antenna also decreases as in fig. 9 .
Table- III: Effect on impedance by varying tag parameters

\begin{tabular}{|l|l|l|}
\hline \multirow{2}{*}{$\begin{array}{l}\text { Variation in } \\
\text { a' }\end{array}$} & \multicolumn{2}{|c|}{ Impedance } \\
\cline { 2 - 3 } & Real & Imaginary \\
\hline $\mathrm{a}=22$ & 7.32 & 168.64 \\
\hline $\mathrm{a}=20$ & 5.54 & 145.26 \\
\hline $\mathrm{a}=18$ & 3.51 & 125.93 \\
\hline \multirow{2}{*}{$\begin{array}{l}\text { Variation in } \\
\text { 'b' }\end{array}$} & \multicolumn{2}{|c|}{ Impedance } \\
\cline { 2 - 3 } & Real & Imaginary \\
\hline $\mathrm{b}=14$ & 207.57 & 796.23 \\
\hline $\mathrm{b}=12$ & 14.64 & 199.74 \\
\hline $\mathrm{b}=10$ & 3.76 & 125.62 \\
\hline
\end{tabular}

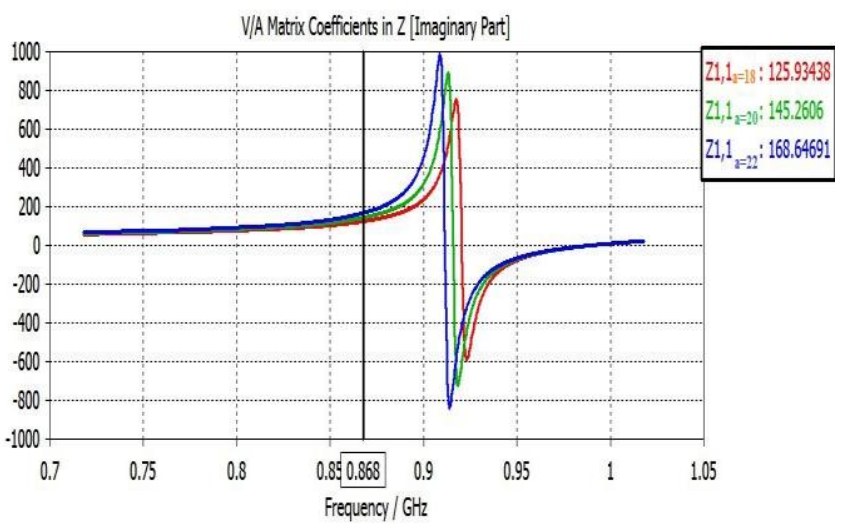

Fig. 9: Impedance variations by varying tag dimensions ' $a$ '

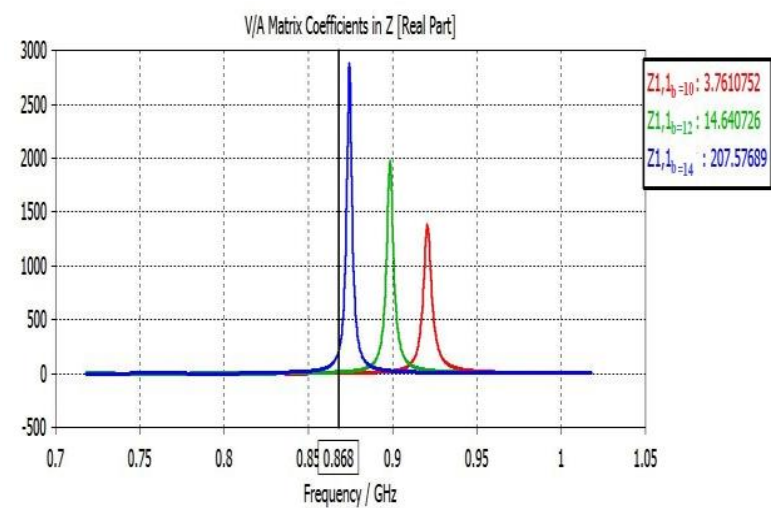

Fig. 10: Impedance variations by varying tag dimensions'b'

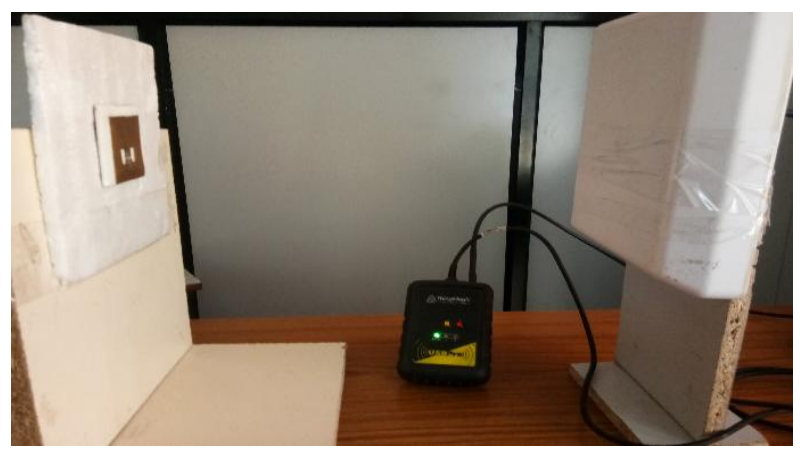

Fig. 11: Experimental Setup for antenna measurements

Published By:

Blue Eyes Intelligence Engineering and Sciences Publication

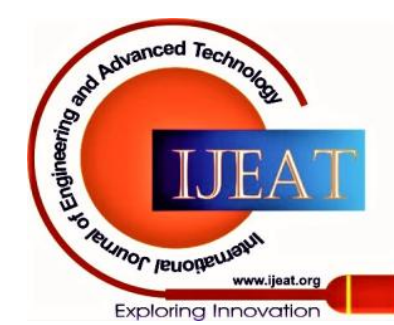




\section{Design of Nested H slot Passive UHF RFID Tag}

The experimental set up as shown in fig. 11 was used to take the antenna measurements. The communication between the RFID reader and RFID tag takes place at $866 \mathrm{MHz}$.

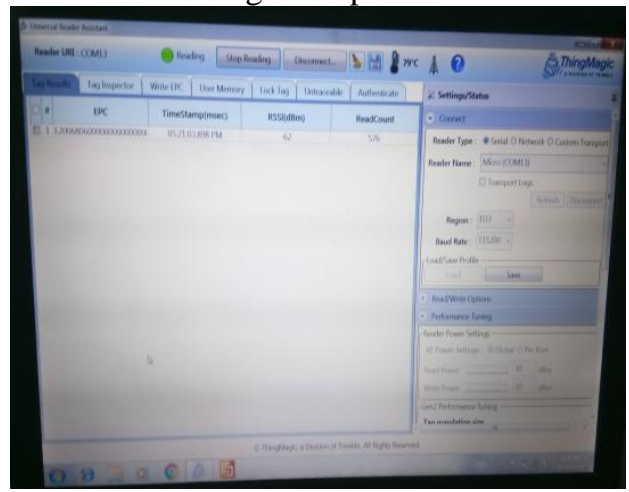

Fig. 12: Tag read by the Thingmagic universal software

An external antenna is used along with the UHF RFID reader to increase the read range. Fig. 12 shows the RSSI reading for the designed tag. More variations in the background and distance of the tag from the reader can be made to have precise results.

\section{CONCLUSION}

The PIFA structure design considerations for RFID tag are discussed in this paper. Prior to the actual fabrication of the PIFA antenna, simulation of the RFID tag antenna is done to get the proper impedance matching of the antenna with the microchip impedance. Finally thefabricated antenna with the same dimensions ispresented. The ground plane separates the antenna from its location, is moreoversuitable to environmental and body-centric applications.

\section{ACKNOWLEDGMENT}

The authors wish to thank their colleague members for their enthusiastic and valuable support.

\section{REFERENCES}

1. K. Finkenzeller, RFID handbook, NewYork, Wiley \& Son, 2000

2. BEST PRACTICES GUIDE, RFID Implementation, Testing \& Deployment

3. Davinder Parkash, "RFID Technology and its Applications: A Review"

4. Aurelian Moraru ; Elena Helerea ; Corneliu Ursachi ; Marius Daniel Călin"RFID system with passive RFID tags for textiles", 10thInternational Symposium on Advanced Topics in Electrical Engineering (ATEE), April 2017.

5. Scientific Research and Essays Vol. 5(10), pp. 1033-1051, 18 May 2010 Available online at http://www.academicjournals.org/SRE ISSN 1992-2248 (C) 2010 Academic Journals

6. Gaetano Marrocco, "The Art of UHF RFID Antenna Design:Impedance-Matching and Size-Reduction Techniques”, IEEE Antennas and Propagation Magazine, Vol. 50, No. 1, February 2008.

7. K. V. Seshagiri Rao, Pavel V. Nikitin, Sander F. Lam, “Antenna Design for UHF RFID Tags: A Review and a Practical Application”, IEEE transactions on antennas and propagation, vol. 53, no. 12, december 2005

8. C. A. Balanis, Antenna Theory Analysis and Design, John Wiley and Sons, Inc., Toronto, Canada, 3rd edition, 2005.

9. Sudha Surwase, Dr. Ravi Yadahalli, Dr. Shankar Nawale "PIFA RFID Tag Antenna Design and Simulationusing CST Microwave Studio”, International Journal of Science and Research (IJSR), Volume 7 Issue 10, October 2018.

\section{AUTHORS PROFILE}

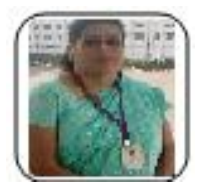

Mrs. SudhaSurwase has completed her post graduation in Electronics Engineering and pursuing PhD at Visvesvaraya Technological University, Belagavi. Her area of research are Antenna designing and Communication. She has more than 10 research papers invarious journals on her credit

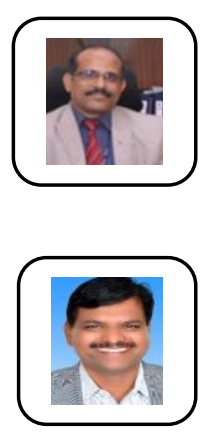

Ravi M. Yadahalli is currently working at SGBIT, Belagavi. He has around 35 years of teaching experience. His area of interest are microwave engineering and antenna designing.He has more than 100 publications in various national and international journals and conferences. He also represented himself in various academic bodies.

Shankar DattatrayaNawalehas professional experience of more than 19 years. Currently working as Principal at NBN Sinhgad College of Engineering, Sholapur. He has more than 40 publications in various journals and conferences. He has visited Foreign Countries like Italy, France, Spain, Switzerland, Malaysia, etc, for the research and symposium work and presented in various sessions as Educational counselor and motivational speaker.He has attended more than 25 training workshops and acquired technical skills related to areas of specialization.

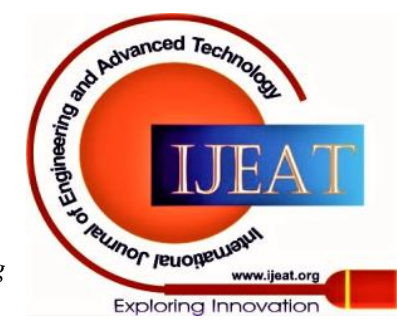

